\title{
An iatrogenic brachial arteriovenous fistula in an infant: A case report
}

\author{
Engin Karakuş ${ }^{1}$, Soysal Turhan² ${ }^{2}$ Onur Işı $k^{3}$ \\ 1Department of Cardiovascular Surgery, Batman Regional State Hospital, Batman, Turkey \\ ${ }^{2}$ Department of Cardiovascular Surgery, Tepecik Training and Research Hospital, İzmir, Turkey \\ ${ }^{3}$ Department of Cardiovascular Surgery, Division of Pediatric Cardiology, Tepecik Training and Research Hospital, İmir, Turkey
}

Received: December 27, 2016 Accepted: May 05, 2017 Published online: April 24, 2019

\begin{abstract}
Acquired arteriovenous fistulas, which are caused by arterial or venous puncture, are common in patients with a history of hospitalization in the intensive care unit for a long time. A four-month-old girl, who was born at 25 weeks and treated in the neonatal intensive care unit for one month due to respiratory distress, was admitted to our clinic with complaints of swelling and bruising on the right arm. Doppler ultrasound revealed an arteriovenous fistula located between the basilic vein and brachial artery, which was surgically treated. Unlike adults, fistulas during infancy may lead to a variety of morbidity, including heart failure, if left untreated. Herein, we report a rare pediatric case of an arteriovenous fistula and discuss our clinical approach.
\end{abstract}

Keywords: Arteriovenous fistula; premature; surgery.

Arteriovenous fistulas (AVFs) are characterized by an abnormal connection between the arterial and venous systems, which can be congenital or acquired. The main causes of AVFs during infancy include arterial or venous punctures. In the majority of patients, medical history reveals premature birth and prolonged intensive care unit stay due to additional lung problems. ${ }^{[1]}$ Herein, we report a rare pediatric case of an arteriovenous fistula who was successfully treated with surgery.

\section{CASE REPORT}

The four-month-old girl was admitted to our clinic with complaints of swelling and bruising on the right arm. She was born 25 weeks old and was treated in intensive care unit for about one month due to respiratory distress. She underwent venous and arterial puncture frequently during this treatment period. The swelling started from the antecubital fossa and spread to the forearm. A strong thrill was obtained with palpation. The peripheral pulses of both upper extremities were palpable and equal. There was a difference in the diameter between the upper extremities, and the antecubital region measurements without difference in length. A hyperdynamic heart peak was present; however, the cardiac-to-thoracic ratio on the cardiac telemetry was within normal limits. Doppler ultrasound revealed a large-base fistula between the brachial artery and the basilic vein in the right antecubital fossa. In addition, brachial venous and arterial diameters increased about two times, compared to the contralateral measurements, and the arterial flow was within the brachial vein, increasing the brachial artery flow. Velocity measurement at the level of the fistula was recorded at $350 \mathrm{~cm} / \mathrm{sec}$ and calculated blood flow at $250 \mathrm{~mL} / \mathrm{min}$.

The patient was scheduled for surgery, and a written informed consent was taken from her parents. Surgical dissection showed a broad base fistula between the median antecubital vein and the brachial artery. The median antecubital vein was seen to be aneurysmatic (Figure 1). Vein was ligated and the aneurysmatic area was excised. Brachial artery was primarily repaired with a 7/0 monofilament suture material. No complications developed after surgery. She was discharged in the second postoperative day following a rapid recovery period.

Corresponding author: Soysal Turhan, MD. SBÜ Tepecik Eğitim ve Araştırma Hastanesi, Kalp ve Damar Cerrahisi Kliniği, 35180 Konak, İzmir, Turkey.

Tel: +90 533 - 2433435 e-mail: sosyal.turhan@gmail.com

\section{Citation:}

Karakuş E, Turhan S, Işık 0. An iatrogenic brachial arteriovenous fistula in an infant: A case report. Cardiovasc Surg Int 2017;4(3):43-44. 


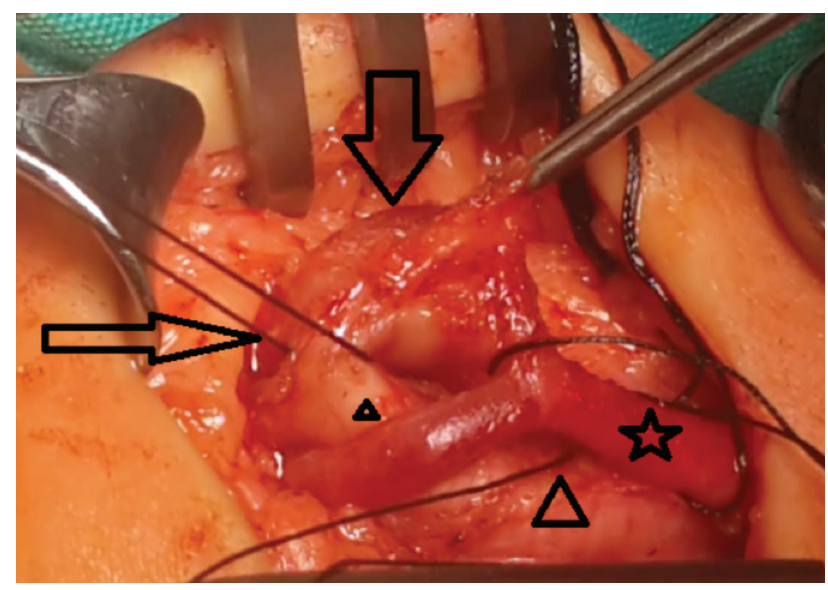

Figure 1. The appearance after the surgical preparation of the antecubital fossa.

Star: Basilic vein; Large and small triangle: Brachial artery; Small arrow: Vena mediana cubiti; Big arrow: Arteriovenous fistula.

\section{DISCUSSION}

Arteriovenous fistulas during childhood are rare pathologies. ${ }^{[2]}$ These fistulas are typically caused by multiple punctures in the arterial and/or venous system. ${ }^{[3]}$ Recognition can be difficult due to their rarity in childhood. However, the thrill on the lesion may be accompanied by hyperdynamic precordium, and cardiac murmur, and enlarged veins on the related extremity. The definite diagnosis can be usually made using Doppler ultrasound. In our case, the suspected AVF was supported with the presence of swelling which caused the diameter difference in the antecubital region, a strong thrill on palpation, and prolonged intensive care hospitalization. The diagnosis was confirmed through ultrasonographic examination.

Sonography is the first choice, as it is non-invasive, does not need sedation or ionizing radiation, is easily accessible, and can make definite diagnosis. Diagnostic criteria with sonographic examination include a low-resistance flow in the artery, highvelocity arterial flow within the vein, and turbulence in the fistula. ${ }^{[4]}$

Clinical management of childhood AVFs is based on adult studies, due to its infrequency and limited data. Therefore, treatment options include surgical excision, transcatheter embolization, ultrasound-guided compression or placement of a covered stent to exclude the lesion. ${ }^{[5]}$ However, we consider that treatment with invasive techniques is not appropriate for infants. Even if the coated stents can be deployed successfully, complications may continue to grow, depending on the need for anticoagulation. Compression on ultrasound guidance may be an appropriate technique for narrow neck lesions; however, it may not be feasible in large and organized fistulas. On the other hand, we suggest that the complication rate of transcatheter embolization for distal vessels in infants would be high. Therefore, we believe that the most appropriate treatment is surgical repair of the artery and vein.

In conclusion, arteriovenous fistulas are infrequent in infants, and the main cause is multiple attempts in the arterial and/or venous system. These fistulas may cause morbidity in infants, leading to various conditions from aesthetic disorders on the limb to high-burdened heart failure. Thus, repair with surgical intervention is an appropriate approach.

\section{Declaration of conflicting interests}

The authors declared no conflicts of interest with respect to the authorship and/or publication of this article.

\section{Funding}

The authors received no financial support for the research and/or authorship of this article.

\section{REFERENCES}

1. Dzepina I, Unusic J, Mijatovic D, Bulic K. Pseudoaneurysm of the brachial artery following venipuncture in infants. Pediatr Surg Int 2004;20:594-7.

2. Tran HS, Burrows BJ, Zang WA, Han DC. Brachial arteriovenous fistula as a complication of placement of a peripherally inserted central venous catheter: a case report and review of the literature. Am Surg 2006;72:833-6.

3. Kotagal M, Reiss A, Vo N, Feldman K, Drugas G, Avansino JR. Iatrogenic arteriovenous fistula in the arm in an infant: diagnostic and therapeutic considerations. J Clin Ultrasound 2012;40:381-4.

4. Li JC, Cai S, Jiang YX, Dai Q, Zhang JX, Wang YQ. Diagnostic criteria for locating acquired arteriovenous fistulas with color Doppler sonography. J Clin Ultrasound. 2002;30:336-42.

5. Kollmeyer KR, Hunt JL, Ellman BA, et al. Acute and chronic traumatic arteriovenous fistulae in civilians. Epidemiology and treatment. Arch Surg 1981;116:697-702. 